\title{
Elevated Endothelin-1 in Intradialytic Hypertension
}

\author{
Rubin Surachno Gondodiputro, Andika Wiratama, Stefanie Yuliana Usman, Erma Arnika \\ Dewi, Evan Susandi, Afiatin, Ria Bandiara \\ Department of Internal Medicine Faculty of Medicine, Universitas Padjadjaran/ \\ Dr. Hasan Sadikin General Hospital Bandung, Indonesia
}

Abstract Objective: To determine the relative change in endothelin-1 (ET-1) during hemodialysis procedure in Stage Five Dialysis-Dependent Chronic Kidney Disease (CKD-5D) patients with and without intradialytic hypertension (IDH).

Methods: This was a cross-sectional, observational study involving 40 CKD-5D patients who received two hemodialysis per week for at least three months at the dialysis unit of Dr. Hasan Sadikin Hospital General Bandung, Indonesia, during September 2016. Subjects were divided into two groups: with IDH $(n=20)$ and without IDH $(n=20)$. Plasma ET-1 level was examined before and after hemodialysis.

Results: There was a significant elevation of ET- 1 level (mean \pm SD pg/mL) between pre- and post-dialysis states in patients with IDH $(3.33 \pm 1.28$ vs. $3.84 \pm 1.75$; relative changes: $15.32 \%, \mathrm{p}=0.013$ ). No change was observed in patients without IDH $(3.99 \pm 2.30$ vs. $4.38 \pm 1.81$; relative changes: $9.77 \%$ $\mathrm{p}=0.083$ ). The post-dialysis absolute ET-1 level was significantly lower in CKD-5D patients with IDH (3.84 \pm 1.75 vs. $4.38 \pm 1.81 ; \mathrm{p}=0.024)$.

Received:

July 10, 2019

Conclusions: There was a significant elevation of ET-1 level in CKD-5D patients with IDH during the hemodialysis procedure at the dialysis unit of Dr. Hasan Sadikin General Hospital Bandung.

Revised:

September 28, 2019 Keywords: Endothelin-1, hemodialysis, intradialytic hypertension

Accepted:

October 19, 2019

pISSN: 2302-1381; eISSN: 2338-4506; http://doi.org/10.15850/ijihs.v7n2.1737

IJIHS. 2019;7(2):102-7

\section{Introduction}

Hemodialysis is the main renal replacement therapy (RRT) option for patients with endstage kidney disease who cannot undergo renal transplantation. Although techniques in hemodialysis are advancing rapidly, intradialytic hypertension (IDH) is still one of the most poorly-recognized complications in patients receiving hemodialysis. ${ }^{1}$ IDH is associated with increased rates of hospitalization, poorer survival rate, and death in dialysis-dependent stage five chronic

Correspondence:

Rubin S. Gondodiputro,

Department of Internal Medicine Faculty of Medicine

Universitas Padjadjaran/Dr. Hasan Sadikin General

Hospital Bandung, Jalan Pasteur No. 38 Bandung, West

Java, Indonesia, e-mail:r.surachno@yahoo.com kidney disease patients (CKD-5D)..$^{2-5}$ IDH occurs in $10-12 \%$ hemodialysis patients. ${ }^{3,6}$

The pathogenesis of IDH in patients undergoing routine hemodialysis has not been fully understood. Many factors are considered to be the cause of this complication. ${ }^{2}$ Studies demonstrated that the endothelin-1 (ET-1) level significantly increases in IDH patients in comparison to controls. ${ }^{7-11}$ In a pathological condition, the ET-1 may induce endothelial dysfunction, increase peripheral resistance, and eventually lead to IDH.,12

A study in Bandung and a study by the Indonesian Renal Registry showed that IDH accounts for $35-36 \%$ of complications in hemodialysis patients. ${ }^{13,14}$ Furthermore, a study which included some hospitals in Bandung showed a different ratio from earlier studies in other countries. ${ }^{14}$ This raises the question of whether there are differences in the cause of high IDH incidence, particularly 
in the ET-1 level as a marker of endothelial dysfunction. Previous studies determined the absolute changes of ET-1 before and after dialysis in patients with IDH and controls. Since many factors may contribute to the ET-1 baseline level alterations, a significant difference in plasma ET-1 may be found in patients with and without IDH. Hence, it is crucial to establish the relative change in the ET-1 level between the two groups during the hemodialysis procedure.

This study aimed to determine the relative change of ET-1 levels in the CKD-5D patients with and without IDH treated at the dialysis unit of Dr. Hasan Sadikin General Hospital Bandung, Indonesia.

\section{Methods}

This study was a cross-sectional observational study on CKD-5D patients who underwent routine hemodialysis twice a week for more than three months in Dr. Hasan Sadikin General Hospital Bandung, Indonesia, during September 2016. From the calculation using the formula below, a minimum of 16 subjects for the group with predictor (IDH) and 16 subjects for the group without predictor (without IDH) were required. The alpha standard deviation was $5 \%$; therefore, the $\mathrm{Z}_{\alpha / 2}$ was 1.96 , and the beta standard deviation was $10 \%$. Hence, the $\mathrm{Z} \beta$ would be 1.28 .

A consecutive sampling technique was applied for subject recruitment. Patients were categorized into the group with IDH $(n=20)$ or without IDH $(n=20)$. The inclusion criteria were adult patients aged 18 years old or older who took anti-hypertensive drugs. Patients who had atrial fibrillation or whose blood pressure (BP) could not be measured by standard procedures were excluded.

Patients' blood pressure was measured before and after each hemodialysis session. IDH was defined as a difference in systolic BP (post-dialytic BP minus pre-dialytic BP) of more than $10 \mathrm{mmHg}$, with a BP of above $130 / 80 \mathrm{mmHg}$ after completing the hemodialysis session. ${ }^{1,3}$ Patient' body weight was measured before and after hemodialysis sessions. The IDWG was calculated as predialysis weight minus post-dialysis weight of the previous hemodialysis session. ${ }^{15}$ The ultrafiltration rate was defined by dividing the ultrafiltration volume $(\mathrm{ml})$ by the length of time of the dialysis session (hours) and target dry weight $(\mathrm{kg}){ }^{16}$

The difference in ET-1 level between the pre- and post-dialysis was evaluated by using the paired T-test. while the comparison of ET-1 level and their changes between IDH and non-IDH groups were performed using the unpaired T-test. $P$-value $<0.05$ was considered statistically significant.

The ethical clearance for this study was obtained from the Ethics Committee of the Faculty of Medicine of Universitas Padjadjaran under the ethical clearance number: LB.04.01/ A05/EC/250/Vll/2016.

\section{Results}

A total of 40 subjects were included in the study, with twenty subjects for each group.

Table 1 presents the baseline characteristics of the study subjects. Other than the interdialytic weight gain (IDWG), ultrafiltration, and history of hypertension in the last one month, the baseline characteristics between the CKD-5D patients with and without IDH were similar.

In subjects with IDH, the mean age was $54 \pm 12$ years old. The mean pre-dialytic and post-dialytic BP in this group were 160/79 $\mathrm{mmHg}$ and 186/89 $\mathrm{mmHg}$, respectively, while the mean dry body weight was $50.2 \pm 10.6 \mathrm{~kg}$.

The mean IDWG was significantly higher $(\mathrm{p}=0.048)$ in subjects without IDH, with $80 \%$ $(\mathrm{n}=16)$ of patients experiencing an increase in IDWG. The mean ultrafiltration volume was also significantly higher $(\mathrm{p}=0.009)$ in subjects without IDH.

On pulse pressure and pulse rate examination, the mean values between subjects with and without IDH were similar $(81 \pm 20 \mathrm{mmHg}$ versus $75 \pm 25 \mathrm{mmHg}$ and $75 \pm 10$ times per minute versus $81 \pm 1175$. respectively). The hematocrit and sodium levels were also found to be similar between the two groups.

Based on the diagnosis of CKD, hypertension was the most common cause $(65 \%)$ in subjects with intradialytic group, followed by diabetic kidney disease (25\%), primary glomerulopathy (5\%), and lupus nephritis (5\%). Whereas, in the group without IDH, the most common cause of CKD was hypertension $(55 \%)$, followed by diabetic kidney disease (25\%), PNC (10\%), and primary glomerulopathy $(10 \%)$.

The history of IDH in the last one month was significantly higher $(\mathrm{p}=0.034)$ in subjects with IDH, occurring 2-9 times a month.

Table 2 shows the ET- 1 level in the study subjects before and after dialysis. In the IDH group, the mean $( \pm$ SD) of pre-dialytic and post-dialytic ET-1 level was $3.33 \pm 1.28 \mathrm{pg} / \mathrm{mL}$ and $3.84 \pm 1.75 \mathrm{pg} / \mathrm{mL}$, respectively, and the 
Table 1 Baseline Characteristics

\begin{tabular}{|c|c|c|c|}
\hline Variable & $\begin{array}{c}\text { IDH } \\
(n=20)\end{array}$ & $\begin{array}{c}\text { Without IDH } \\
(n=20)\end{array}$ & P-value \\
\hline $\begin{array}{l}\text { Age (years) } \\
(\text { mean } \pm S D)\end{array}$ & $54 \pm 12$ & $52 \pm 14$ & $0.730 *$ \\
\hline $\begin{array}{l}\text { Gender }(n, \%) \\
\text { Male } \\
\text { Female }\end{array}$ & $\begin{array}{l}8(40.0) \\
12(60.0)\end{array}$ & $\begin{array}{l}12(60.0) \\
8(40.0)\end{array}$ & $0.206^{\dagger}$ \\
\hline $\begin{array}{l}\text { Pre-dialytic Blood Pressure } \\
\text { (mean } \pm \text { SD; mmHg) } \\
\text { Systolic } \\
\quad \text { Diastolic }\end{array}$ & $\begin{array}{c}160 \pm 22 \\
79 \pm 9\end{array}$ & $\begin{array}{l}158 \pm 26 \\
84 \pm 11\end{array}$ & $\begin{array}{l}0.835^{*} \\
0.118^{*}\end{array}$ \\
\hline $\begin{array}{l}\text { Hemodialysis Duration (months) } \\
\text { (median (min-max)) }\end{array}$ & $24(3-77)$ & $27(3-87)$ & $0.797^{\ddagger}$ \\
\hline $\begin{array}{l}\text { Dry Weight } \\
\text { (mean } \pm \text { SD; kg) }\end{array}$ & $50.2 \pm 10.6$ & $57.1 \pm 15.5$ & $0.107^{*}$ \\
\hline $\begin{array}{l}\text { IDWG } \\
\qquad \begin{array}{l}\text { (mean } \pm S D) \\
\text { Elevated } \\
\text { Not elevated }\end{array}\end{array}$ & $\begin{array}{c}2.9 \pm 1.1 \\
13(65.0) \\
7(35.0)\end{array}$ & $\begin{array}{c}3.6 \pm 0.9 \\
16(80.0) \\
4(20.0)\end{array}$ & $\begin{array}{c}0.048^{* \pi} \\
0.288^{\dagger}\end{array}$ \\
\hline $\begin{array}{l}\text { Ultrafiltration } \\
\qquad \text { (mean } \pm \text { SD; ml/hour } / \mathrm{kg}) \\
\text { Elevated } \\
\text { Not elevated }\end{array}$ & $\begin{array}{c}3.240 \pm 981 \\
17(85.0) \\
3(15.0)\end{array}$ & $\begin{array}{c}4.055 \pm 882 \\
17(85.0) \\
3(15.0)\end{array}$ & $\begin{array}{l}0.009^{* ף} \\
1.000^{\S}\end{array}$ \\
\hline $\begin{array}{l}\text { Pulse Pressure } \\
\text { (mean } \pm \text { SD; mmHg) } \\
\text { Elevated } \\
\text { Not elevated }\end{array}$ & $\begin{array}{c}81 \pm 20 \\
19(95.0) \\
1(5.0)\end{array}$ & $\begin{array}{c}75 \pm 25 \\
19(95.0) \\
1(5.0)\end{array}$ & $\begin{array}{l}0.363^{*} \\
1.000^{\S}\end{array}$ \\
\hline $\begin{array}{l}\text { Pulse Rate } \\
\text { (mean } \pm \text { SD; beat per minute) } \\
\text { Elevated } \\
\text { Not elevated }\end{array}$ & $\begin{array}{c}75 \pm 10 \\
7(35.0) \\
13(65.0)\end{array}$ & $\begin{array}{c}81 \pm 11 \\
12(60.0) \\
8(40.0)\end{array}$ & $\begin{array}{l}0.082^{*} \\
0.113^{\dagger}\end{array}$ \\
\hline $\begin{array}{l}\text { Hematocrit } \\
\quad(\text { mean } \pm \text { SD, \%) } \\
\text { Elevated } \\
\text { Not elevated }\end{array}$ & $\begin{array}{c}28 \pm 4 \\
6(30.0) \\
14(70.0)\end{array}$ & $\begin{array}{c}30 \pm 5 \\
8(40.0) \\
12(60.0)\end{array}$ & $\begin{array}{l}0.128^{*} \\
0.507^{\dagger}\end{array}$ \\
\hline $\begin{array}{l}\text { ESA therapy } \\
\text { Yes } \\
\text { No }\end{array}$ & $\begin{array}{c}4(20.0) \\
16(80.0)\end{array}$ & $\begin{array}{c}3(15.0) \\
17(85.0)\end{array}$ & $1.000^{\S}$ \\
\hline $\begin{array}{l}\text { Diagnosis } \\
\text { Hypertension } \\
\text { Diabetic Kidney Disease } \\
\text { Chronic Pyelonephritis } \\
\text { Primary Glomerulopathy } \\
\text { Lupus nephritis }\end{array}$ & $\begin{array}{c}13(65.0) \\
5(25.0) \\
0(0.0) \\
1(5.0) \\
1(5.0\end{array}$ & $\begin{array}{l}11(55.0) \\
5(25.0) \\
2(10.0) \\
2(10.0) \\
0(0.0)\end{array}$ & $0.478^{\dagger}$ \\
\hline $\begin{array}{l}\text { History of IDH in the last one month } \\
\text { (median (min-max)) }\end{array}$ & $4(2-9)$ & $3(1-5)$ & $0.034^{\ddagger \pi}$ \\
\hline
\end{tabular}

SD: standard deviation; ESA: Erythropoietin Stimulating Agents; analysis was performed using ${ }^{*} \mathrm{~T}$-test, ${ }^{\dagger}$ Chi Square, ${ }^{\ddagger}$ Mann Whitney, ${ }^{\S}$ Fisher Exact, "statistically significant ( $\left.\mathrm{p}<0.05\right)$; IDWG = Interdialytic Weight Gain 
Rubin Surachno Gondodiputro, Andika Wiratama, et al.

Table 2 Endothelin-1 Level

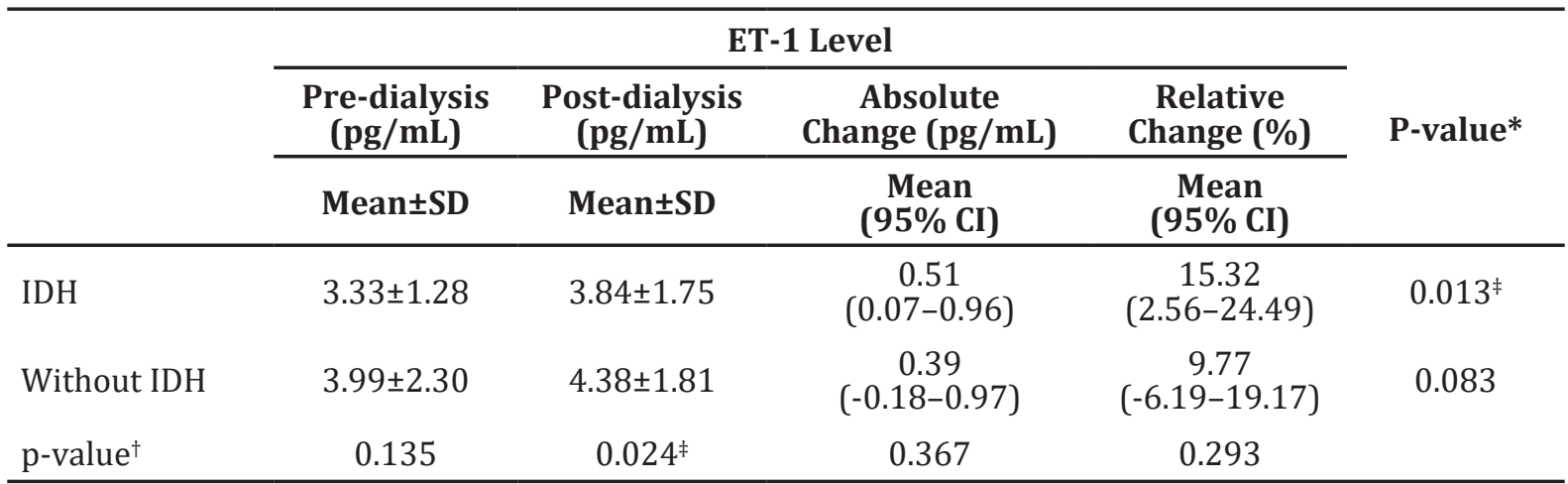

SD: Standard Deviation; CI: Confidence Interval; analysis were performed using ${ }^{*}$ Paired t-test, ${ }^{\dagger}$ Independent t-test, ${ }^{\ddagger}$ statistically significant $(\mathrm{p}<0.05)$

mean absolute change of the ET- 1 level in this group was $0.51 \mathrm{pg} / \mathrm{mL}$ (95\% CI: $0.07-0.96 \mathrm{pg} /$ $\mathrm{mL})$, with a relative change of $15.32 \%(95 \%$ CI: -6.19-19.17\%). The mean absolute change of post-dialytic ET-1 level was significantly higher when compared to the pre-dialytic level $(p=0.013)$, but the relative change was not significantly altered ( $p>0.05)$.

In the CKD-5D patients without IDH, the mean $( \pm$ SD) pre-dialytic ET-1 level was $3.99 \pm 2.30 \mathrm{pg} / \mathrm{mL}$, while the post-dialytic level was $4.38 \pm 1.81 \mathrm{pg} / \mathrm{mL}$. The mean absolute change of the ET-1 level in this group was $0.39 \mathrm{pg} / \mathrm{mL}$ (95\% CI: $-0.18-0.97 \mathrm{pg} / \mathrm{mL}$ ), and the relative change was $9.77 \%$ (95\% CI: 6.25$36.72 \%$ ). However, neither absolute change nor relative change of ET-1 level differed significantly between pre and post-dialysis $(\mathrm{p}=0.083)$ groups.

The pre-dialytic ET-1 level was not significantly different between subjects with IDH and without IDH. In the post-dialytic state, a significantly higher ET-1 level in the IDH group was observed $(p=0.024)$. However, the absolute and relative changes were not significantly different.

\section{Discussion}

In this study, the subjects' mean age was slightly higher in those with IDH when compared to the subjects without IDH, although no significant mean age difference was identified between the two groups. Inrig et al. previously presented that IDH is commonly found in elderly CKD subjects who had routine hemodialysis. Endothelial dysfunction in elderly patients was thought to be a risk factor for IDH. ${ }^{3}$

The mean dry weight of subjects with IDH

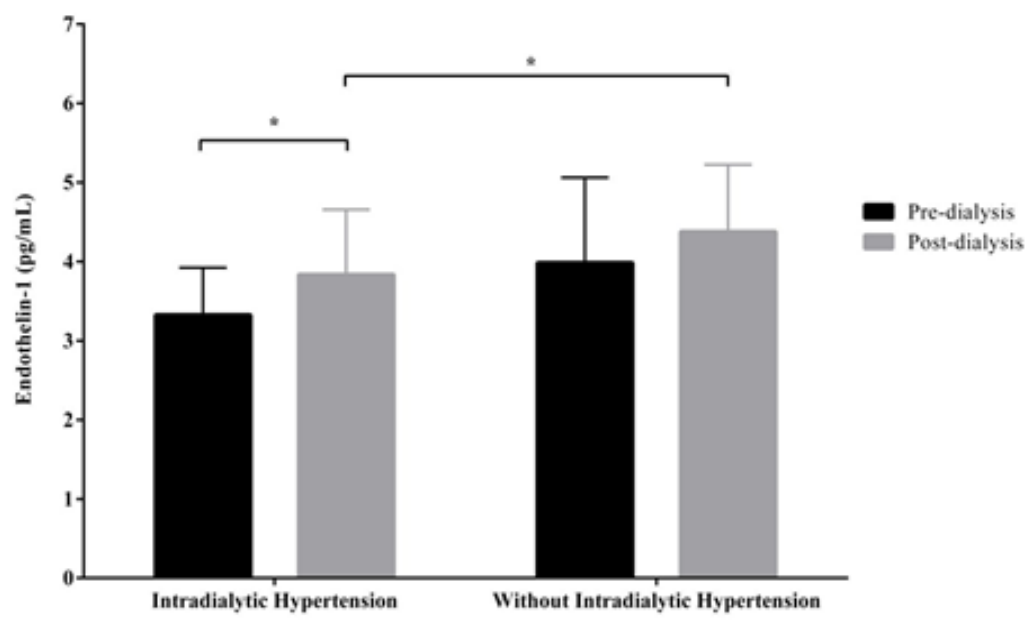

Fig. Absolute Change of ET-1 Level Before and After Dialysis 
was lower than that of subjects without IDH. This result was in accordance with a previous study by Van Buren et al., although both studies showed no significant difference between the two groups. ${ }^{6}$

This study demonstrated that the absolute values of IDWG and ultrafiltration were significantly lower in subjects with IDH, albeit this was not the case in the relative change. The IDWG and ultrafiltration have been proposed to be involved in the pathogenesis of IDH. Patients with IDH had lower body weight, smaller IDWG, and slower ultrafiltration rates. IDH patients tend to gain less weight between procedures, making it necessary to prescribe slower ultrafiltration. The smaller the ultrafiltration rate, the less volume depletion occurs. This condition promotes IDH. ${ }^{2,6}$

The absolute value of IDWG and ultrafiltration in subjects with IDH was significantly lower. This result was similar to previous data. ${ }^{4,6,17}$ However, a contradicting result from a recent large cohort study showing that the higher the IDWG, both absolute and relative, the more frequent the intradialytic event is. ${ }^{18}$ Therefore, the relation between IDWG and intradialytic blood pressure is still controversial. Lopez et al. stated that excessive IDWG is a sign of excess sodium level and water, which could cause fluid overload. This might contribute to arterial hypertension in CKD patients undergoing routine hemodialysis. ${ }^{19}$ Other studies found that hypervolemia and body weight have no effect on systolic and diastolic blood pressures in patients with routine hemodialysis and that there is no direct association between IDWG and blood pressure in dialysis patients. ${ }^{20,21}$ Of the few previous studies, no conclusive evidence can be drawn. This is likely due to the complexity of hypertension pathophysiology.

In this study, the post-dialysis ET-1 level was higher in patients without IDH. However, the pre-dialysis level of ET-1 was similar in patients with or without IDH. This was in accordance with earlier studies. ${ }^{8,10}$ hematocrit (Hct However, in contrary to this study, previous studies demonstrated that the postdialysis ET-1 level is significantly higher in patients with IDH. ${ }^{8,10}$

This discordance may be partially explained by the higher absolute values of IDWG and ultrafiltration in patients without IDH in this study. As it is previously mentioned, one large cohort study associated the increase in IDWG and ultrafiltration with a greater IDH incidence. In addition, ultrafiltration is shown to affect the ET- 1 release in hemodialysis patients. ${ }^{22}$
In this study, a greater ultrafiltration absolute value found in patients without IDH may cause a higher ET-1 outcome. The increase in ET-1 levels was not only observed in the patients with IDH but also in patients without IDH.

Another plausible explanation is the discrepancy in the absolute ET-1 values across studies. Although using the same reagent (R\&D System Inc., Minneapolis, MN, USA), the ET-1 levels obtained vary widely. Chou et al. found a much higher average level of ET-1. (510.9 \pm 43.3 vs. $276.7 \pm 30.1 \mathrm{pg} / \mathrm{ml}$ in subjects with and without IDH, respectively) ${ }^{8}$ While Teng et al. ( $4.09 \pm 2.06$ vs. $2.75 \pm 1.34 \mathrm{pg} / \mathrm{mL})$ showed similar values to this study. ${ }^{10}$ This might be influenced by different sampling techniques or racial factors, which had not been well studied.

A significant ET-1 level elevation was demonstrated in patients with IDH in this study; however, no significant alteration was seen in patients without IDH. The absolute change was also significantly elevated, but this was not the case in the relative change of the ET- 1 level. This is parallel with previous research, which revealed a significant elevation of ET-1 level in the IDH group albeit no change was observed in the control group. ${ }^{8,10}$ These results indicate a relationship between IDH incidence and ET-1 level.

There are limitations to this study. The sampling was performed consecutively, not randomly. In addition, the dry weight was only measured clinically, and no accurate tool with the ability to measure the volume of fluid in the body (multiple frequency bioimpedance spectroscopy) was used.

In summary, there is a significant elevation of the ET-1 level in CKD-5D patients with IDH during the hemodialysis procedure. However, no CKD-5D patients in this study population, both with and without IDH, experience a relative change in the ET-1 level. A cohort study is needed in patients with elevated ET-1 levels to evaluate the incidence of subsequent IDH in order to assess whether ET-1 levels can predict an IDH event. Furthermore, a comprehensive multivariate study is needed to establish the relationship between risk factors for IDH, both for clinical and biochemical risk factors.

\section{References}

1. Rocco M, Daugirdas JT, Depner TA, Inrig J, Mehrotra R, Rocco MV, et al. KDOQI Clinical Practice Guideline for Hemodialysis Adequacy: 2015 Update. Am J Kidney Dis. 2015;66(5):884-930. 
2. Locatelli F, Cavalli A, Tucci B. The growing problem of intradialytic hypertension. Nat Rev Nephrol. 2010;6(1):41-8.

3. Inrig JK, Patel UD, Toto RD, Szczech LA. Association of blood pressure increases during hemodialysis with 2-year mortality in incident hemodialysis patients: a secondary analysis of the Dialysis Morbidity and Mortality Wave 2 Study. Am J Kidney Dis. 2009;54(5):881-90.

4. Choi CY, Park JS, Yoon KT, Gil HW, Lee EY, Hong SY. Intra-dialytic hypertension is associated with high mortality in hemodialysis patients. PloS one. 2017;12(7):e0181060.

5. Raikou VD, Kyriaki D. The association between intradialytic hypertension and metabolic disorders in end stage renal disease. Int J Hypertens. 2018;2018:1681056.

6. Van Buren PN. Pathophysiology and implications of intradialytic hypertension. Curr Opin Nephrol Hypertens. 2017;26(4):303-10.

7. Hompesch C, Ma T-w, Neyra JA, Ripley L, Xiao G, Inrige J, et al. Comparison of ambulatory blood pressure patterns in patients with intradialytic hypertension and hemodialysis controls. Kidney Blood Press Res. 2016;41(3):240-9.

8. Chou KJ, Lee PT, Chen CL, Chiou CW, Hsu CY, Chung HM, et al. Physiological changes during hemodialysis in patients with intradialysis hypertension. Kidney Int. 2006;69(10):18338.

9. Hajal J, Saliba Y, Joubran N, Sleilaty G, Chacra $D$, Assaad S, et al. New insights into the pathogenesis of intradialytic hypertension. Open Urol Nephrol J. 2018;11:87-99.

10. Teng J, Tian J, Lv WL, Zhang XY, Zou JZ, Fang $\mathrm{Y}$, et al. Inappropriately elevated endothelin-1 plays a role in the pathogenesis of intradialytic hypertension. Hemodialysis international International Symposium on Home Hemodialysis. 2015;19(2):279-86.

11. Gutiérrez-Adrianzén OA, Moraes MEA, Almeida AP, Lima JWO, Marinho MF, Marques AL, et al. Pathophysiological, cardiovascular and neuroendocrine changes in hypertensive patients during the hemodialysis session. J Hum Hypertens. 2015;29:366-72.

12. Chazot C, Jean G. Intradialytic hypertension: it is time to act. Nephron Clinical practice. 2010;115(3):c182-8.

13. Indonesian Society of Nephrology. Report of Indonesian renal registry: program Indonesian renal registry (IRR).

14. Afrianti R, Ruly R, Afiatin. Gambaran faktorfaktor risiko klinis kejadian hipertensi intradialitik penderita penyakit ginjal kronik stadium $\mathrm{V}$ pada unit dialisis rumah sakit di bandung. Bandung: Universitas Padjadjaran; 2016.

15. Fouque D, Vennegoor $M$, ter Wee $P$, Wanner C, Basci A, Canaud B, et al. EBPG guideline on nutrition. Nephrology, dialysis, transplantation: official publication of the European Dialysis and Transplant Association - European Renal Association. Nephrol Dial Transplant. 2007;(22 Suppl 2):ii45-87.

16. Ipema KJR, Kuipers J, Westerhuis R, Gaillard CAJM, van der Schans CP, Krijnen WP, et al. Causes and Consequences of Interdialytic weight gain. Kidney Blood Pressure Res. 2016;41(5):710-20.

17. Meyring-Wosten A, Luo Y, Zhang H, Preciado $\mathrm{P}$, Thijssen S, Wang $\mathrm{Y}$, et al. Intradialytic hypertension is associated with low intradialytic arterial oxygen saturation. Nephrol Dial Transplant. 2018;33(6):1040-5.

18. Stefansson BV, Brunelli SM, Cabrera C, Rosenbaum D, Anum E, Ramakrishnan K, et al. Intradialytic hypotension and risk of cardiovascular disease. Clinical journal of the American Society of Nephrology: CJASN. 2014;9(12):2124-32.

19. Lopez-Gomez JM, Villaverde M, Jofre R, Rodriguez-Benitez P, Perez-Garcia R. Interdialytic weight gain as a marker of blood pressure, nutrition, and survival in hemodialysis patients. Kidney Int Suppl. 2005;(93):S63-8.

20. Khalaj A-R, Sanavi S, Afshar R, Rajabi M-R. Effect of intradialytic change in plasma volume on blood pressure in patients undergoing maintenance hemodialysis. J Lab Physicians. 2010;2(2):66-9.

21. Testa A, Plou A. Clinical determinants of interdialytic weight gain. Journal of renal nutrition: the official journal of the Council on Renal Nutrition of the National Kidney Foundation. 2001;11(3):155-60.

22. Surdacki A, Sulowicz W, Wieczorek-Surdacka E, Herman ZS. Effect of a hemodialysis session on plasma levels of endothelin-1 in hypertensive and normotensive subjects with end-stage renal failure. Nephron. 1999;81(1):31-6. 